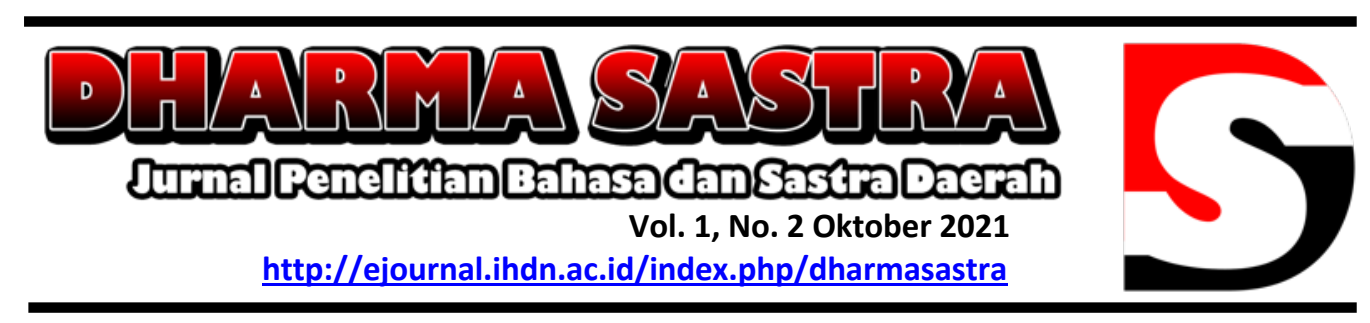

\title{
Nilai- Nilai yang Terkandung dalam Satua Cetrung
}

\section{Ni Made Ari Tresnawati}

\section{Universitas Hindu Negeri I Gusti Bagus Sugriwa Denpasar, Email; deari.tresna90@gmail.com}

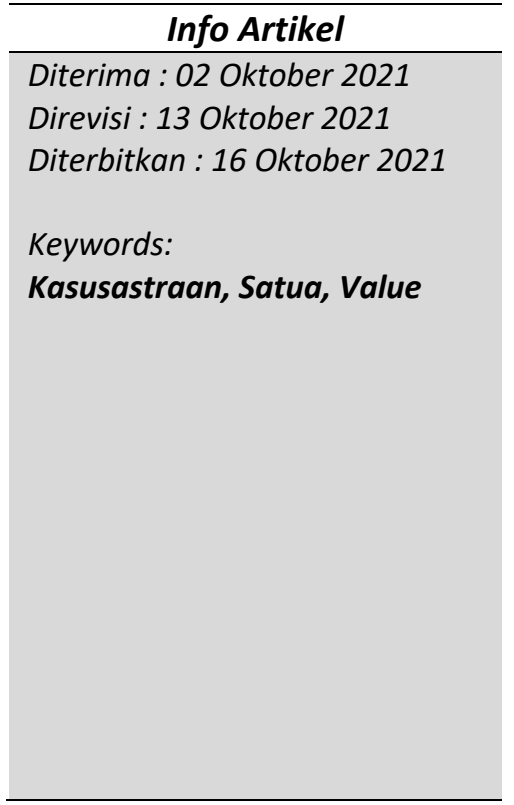

\begin{abstract}
Balinese literature is historical evidence of Balinese society, which is one part of the national culture which is domiciled as a vehicle for cultural expression which contains aesthetic, religious, and socio-political processing of Balinese society. Satua Bali is one of the traditional Balinese literatures called oral literature. Satua is also a means of moral and character education in children that must be instilled from an early age to shape children's character. By providing indirect guidance through satua (fairy tales), the character, mentality, attitude, and behavior of the child will definitely be affected as well. This is because the aspect of the value of the unit is indeed very high, useful, and useful. Satua Cetrung is a literary work that contains noble values and can be used as a guide in life. The values contained include: religious, logical values , and ethical values.
\end{abstract}

\section{Pendahuluan}

Mata pelajaran muatan lokal bahasa Bali merupakan mata pelajaran muatan lokal yang wajib diajarkan pada satuan pendidikan di provinsi Bali. Tujuan pengajaran muatan lokal Bahasa Bali agar siswa menghargai dan mengembangkan bahasa Bali sebagai bahasa ibu, bahasa pergaulan, dan bahasa pengantar kebudayaan daerah Bali. Siswa diharapkan mampu memahami bahasa dan sastra Bali dari segi bentuk, makna, dan fungsi serta menggunakannya dengan tepat dan kreatif untuk bermacam-macam tujuan, keperluan, dan keadaan.

Sastra Bali merupakan bukti historis masyarakat Bali, yang merupakan salah satu bagian dari kebudayaan nasional berkedudukan sebagai wahana ekspresi budaya yang di dalamnya mengandung pengolahan estetik, religius, dan sosial politik masyarakat Bali 
(Dispora prov. Bali, 2008: 4). Dengan mempelajari bahasa Bali, khususnya kesusastraan Bali, siswa diharapkan mampu menumbuhkan minat berkesenian dan ikut serta melestarikan kebudayaan Bali.

Menurut Suwija (2011: 73) kata kasusastran berasal dari kata sastra yang berarti ajaran mendapat awalan su- dan konfiks ka-an. Awalan su- berarti baik, sedangkan konfiks ka-an berarti keadaan. Jadi, kasusastran dapat diartikan keadaan ajaran yang baik. Berdasarkan arti kata kasusastran tersebut, maka dapat diartikan kasusastran Bali adalah segala jenis ajaran atau pengetahuan yang baik, hasil karya para sastrawan Bali yang ditulis dengan bahasa Bali baik yang ditulis dengan aksara Bali maupun huruf latin. Sastra Bali tidak hanya menggunakan bahasa Bali saja, namun ada juga yang menggunakan bahasa Kawi atau bahasa Jawa Kuna. Jadi, kasusastran Bali adalah segala jenis ajaran atau pengetahuan yang baik, ditulis dengan bahasa Bali dan Kawi dan diwarisi sampai saat ini, baik yang menggunakan aksara Bali maupun huruf latin. Berdasarkan jamannya, kasusastran Bali dibagi menjadi dua bagian yaitu kasusastran Bali Purwa (sastra tradisional) dan kasusastran Bali Anyar (sastra modern). Kasusastran Bali Purwa dapat dibagi lagi yang terdiri dari gancaran, palawakya, dan tembang.

Salah satu bagian dari kasusastraan Bali adalah satua. Dalam bahasa Bali, satua merupakan bagian dari kasusastraan Bali Purwa yang berupa gancaran (prosa). Satua merupakan media pendidikan untuk membantu para guru atau pendidik untuk menanamkan pendidikan kepada anak di sekolah, sedangkan di rumah tangga, orangtua mendidik anaknya dapat melalui satua-satua, yaitu satua yang banyak mengandung nasihat-nasihat atau amanat yang baik, agar anak dapat mengaplikasikannya ke dalam kehidupan sehari-hari. Dengan memberikan bimbingan secara tidak langsung melalui satua (dongeng), maka watak, mental, sikap, dan tingkah laku anak itu pasti akan terpengaruh juga. Hal ini karena aspek nilai satua tersebut memang sangat tinggi, berfaedah, dan berguna. Melalui satua, anak akan dapat membandingkan perbuatan yang telah pernah dilakukan dan perbuatan yang belum dilakukan dengan pertimbangan pada nasihat atau amanat dalam satua itu. Jadi, dapat dikatakan bahwa satua dapat dijadikan sebagai landasan pembentukan karakter dan sikap anak (siswa) dalam berperilaku, hal ini karena satua mengandung nilai-nilai pendidikan dan amanat atau nasihat-nasihat yang patut digugu dan ditiru (Dewi, 2019).

Satua berperan sebagai sarana komunikasi, pengajaran, pendidikan bagi anak- anak maupun masyarakat bahkan pada saat belum di kenal tulisan, maupun pendidikan formal seperti sekarang ini. Saat ini ide-ide serta kandungan berupa pesan atau amanat dalam satua sarat akan nilai-nilai yang berguna bagi kemanusiaan. Keunikan lain dari satua yaitu, dari penyebaran secara lisan yang menyebabkan banyak terdapat kemiripan cerita di daerah-daerah yang berbeda, atau disebut dengan varian (Arissandi, Setiawan, and Wiludjeng, 2019).

Dalam pendidikan tradisional Bali mengenal istilah malajah sambil magending, magending sambil malajah, malajah sambil mapalianan, mapalianan sambil malajah, dan sebagainya. Dimana salah satu bentuk malajah (belajar) adalah melalui satua. Satua yang notabena merupakan inti sari dari pengajaran ajaran agama hindu namun dikemas dengan cara yang sederhana (Tinggi et al., 2021). 
Satua Bali adalah salah satu produk seni tradisional Bali yang diberikan kepada anak-anak, namun sayang keberadaan pengaplikasian satua Bali saat ini sangat minim padahal satua Bali merupakan warisan leluhur yang patut dijaga dan dilestarikan keberadaannya mengingat nilai-nilai moral yang terkandung didalam satua Bali ini sangat baik dalam pembentukan karakter anak serta dapat pula menanamkan rasa penghargaan anak terhadap budaya dan kebiasaan setempat (Melestarikan and Bali, 2021).

Penanaman ajaran moral melalui nilai-nilai dalam satua sangatlah penting untuk dilakukan pada anak-anak. Upaya penggalian, sosialisasi, serta internalisasi tata nilai tersebut di kalangan anak-anak tentu harus diawali dengan pemahaman masyarakat tentang amanat melalui analisis nilai satua itu sendiri (Pradnya Paramitha, 2020).

Di antara sekian banyak satua-satua yang hidup dan berkembang di masing-masing daerah di Bali, penulis akan menguraikan nilai-nilai pendidikan karakter yang terdapat pada satua yang berjudul Cetrung. Satua ini dipilih sebagai objek penelitian karena satua tersebut mengandung makna kehidupan tersendiri bagi masyarakat Bali. Disamping itu fenomena yang diungkap di dalam Satua Cetrung menggambarkan gejolak sosial yang ada dalam kehidupan masyarakat Bali, terutama terlihat dalam cerita yang menggambarkan suasana pertanian di Bali. Struktur dan nilai-nilai pendidikan karakter yang terkandung dalam Satua Cetrung patut diketahui, dimana nilai-nilai tersebut dapat digunakan sebagai pedoman oleh masyarakat Bali dan dapat diterapkan dalam kehidupan sehari-hari. Dalam menerapkannya juga harus didasari dengan kecerdikan, seperti halnya karakter cerdik yang dimiliki oleh tokoh-tokoh yang terdapat dalam Satua Cetrung tersebut. Kecerdikan itulah yang digunakannya untuk menyelesaikan masalah yang sedang dihadapinya. Hal semacam ini sangat perlu untuk dibicarakan, sebab permasalahan ini masih tampak dalam kehidupan masyarakat Bali.

\section{Metode}

Metode adalah suatu cara yang dipergunakan untuk mencapai tujuan penelitian. Secara umum metode penelitian diartikan sebagai cara ilmiah untuk mendapatkan data dengan tujuan dan kegunaan tertentu (Sugiyono, 2012: 3). Penggunaan metode dalam sebuah penelitian memiliki nilai yang sangat penting dan strategis karena metode merupakan jalan yang harus ditempuh atau dilalui dalam melakukan penelitianpenelitian ilmiah.

Berdasarkan tujuannya, penelitian ini tergolong penelitian dasar (Basic Research) yang bertujuan untuk mengembangkan ilmu pengetahuan. Penelitian ini menggunakan metode deskriptif kualitatif dengan model penelitian analisis konten. Metode deskriptif kualitatif yang digunakan dalam penelitian ini bertujuan untuk memperoleh data sehingga mempermudah proses analisis. Metode analisis konten digunakan untuk menganalisis suatu karya sastra agar diketahui isi dan makna yang terkandung dalam karya sastra tersebut. Penelitian ini merupakan penelitian perpustakaan yang menggunakan data primer berupa buku cerita yang berjudul Pupulan Satua Bali II yang disusun oleh Dewan Pendidikan dan Klinik Pendidikan Kabupaten Tabanan tahun 2017. 


\section{Pembahasan}

\section{Sinopsis Satua Cetrung}

Satua Bali yang berjudul "Cetrung" merupakan salah satu judul satua pada buku Pupulan Satua Bali II yang disusun oleh Dewan Pendidikan dan Klinik Pendidikan Kabupaten Tabanan tahun 2017. Satua-satua pada buku tersebut ditulis oleh 10 besar pemenang dalam lomba menulis satua Bali, yang diikuti oleh guru sekolah dasar seKabupaten Tabanan. Berikut adalah sinopsis Satua Cetung.

Wenten kedis cerik ane maadan I Kedis Cetrung. Amah-amahane uled. Ia masebun di don padine miwah di don ambengane ane mentik di pundukan carike. Munyine jangih ngulangunin pesan. Liyu anake nyengguhang kedise ento pinaka unenunen Ida Bhatari Sri.

Caritayang mangkin, I Kedis Cetrung ane masebun di carik Nanang Brangkuse sedek nguci magendingan sambilanga ngempu pianakne ane enu cerik. Dugase ento Nanang Brangkus ajake memene sedek ngalap kacang. Nanag Brangkus nyambatang teken Memen Brangkus lakar manyi padine sawireh suba kuning-kuning buin mani semengan.

Makejang raos Nanang Brangkus ajake memene padingehanga teken I Cetrung. Tengkejut I Cetrung, lantas ngencolang makeber ngungsi sebune. I Cetrung luh ngeling sigsigan wireh takut lakar nemu sengkala. I Cetrung Luh nyatua teken Cetrung muani mani padine ene lakar panyine. Sinah suba panake lakar ejuka, sawireh ia tonden kerep bulunne, tusing nyidang makeber joh.

Cetrung muani milu sedih wireh tusing nyidang ngisidang, ngeberang panakne uli di sebune. Saget teka I Kidang nyongkok di sampingan sebun I Cetrunge. Lantas matakon nguda Cetrung kaliwat sedih. Cetrung nyatuayang unduk Nanang Brangkus lakar manyi padine buin mani semengan, krana pianakne Cetrung nu cerik tonden kerep bulune, sinah ia tusing nyidang makeber joh.

I Kidang bengong minehin pakeweh ane nibenin sawitrane. Tumben jani I Cetrung sebet buka kene. la dot pesan nulungin i Cetrung la tusing lascarya nepukin panak sawitrane katiben baya. Lantas I Kidang ngae daya upaya apanga nyidang nulungin I Cetrung. Kidang Kisis-kisi ngorahin pangrencanane teken Cetrung. I Cetrung lega pesan ningehang sawitrane lakar mapitulung gumanti panakne tusing nepukin sengkala. Lantas is ngalihang panakne amah-amahan kanti betek.

Kacerita buin manine pasemengan, suryane kangin endag nyundarin jagate. Damuhe pakenyitnyit di muncuk-muncuk don padange satonden ulung ampehang angin. I kedis Keperit, Tangsiah, Kepetingan, keto masih kedis Kebondol, kedis Gelatik, Kukur, paseliwer makeber duwur carike, pada ngungsi tongos ngalih amah. I kedis Cetrung matinggah di muncuk tungguhan kacange bayune runtag, ngantosang I Kidang.

Kacerita para paderepe suba ngebek di carik Nanang Brangkuse. Ada ane negak di sisin abiane, ada ane nyongkok, sambilang ngagah takilan, marerod di pundukane. Ngajengan nasi panyemeng. Men Brangkus nepukin ada kidang ane sesai ngamah buah kacangne, lantas nyerit ngaukin pisagane. Sambilanga nujuhang I Kidang majalan adeng-adeng pesu uling carike ane linggah. Makejang paderepe nyelingah bangun nyagjegin I Kidang. Ada ane nyemak kayu, ada ane nyemak sanan, ada ane nyemak tali ngae jaet, mabyayuhan saling sautin paderepe ngendahang I Kidang. 
I Kidang majalan ngencolan ngejohin sebun I Cetrunge. Disubane joh I Kidang tolah tolih mapi-mapi tuara rungu teken para paderepe ane ngendehang tur mabudi lakar ngejuk ia. Lantas I Kidang macelep ka tengah carike. Kisi-kisi men Brangkus nujuhang tongos I Kidang mengkeb teken Nanang Brangkus. Saget nungkalik men Brangkus tomploka baan ikidang kanti ulung meleging.

I Cetrung ngajak panakne, kacerita suba joh makecog-kecog nelingkap di padine ngalahin sebune. Sawetara buin telung depa ia suba lakar teked di padang gelagahe ane bet pesan. Cetrung muani ngorahin Cetrung Luh ngwangsitin I Kidang apanga melaib jo mapan ia jejeh pesan, nepukin paderepe ngancan-ngancan galak morosin I Kidang. Sambilan ngorahang dewekne suba selamet. Cetrung ane luh lantas makeber ngungsi I Kidang nekedang pabesen somahne. Cetrung Luh ngorahang suksma baan pitulung I Kidang. I Kidang milu bagia ningehang unduk pianak Cetrunge suba rahayu. Lantas I Kidane malaib nyilib macelep $k n$ alase.

Nanang Brangkus nepukin I Kidang macelep ka tengah alase tur matujuhan ngawangsitin nyama brayane unduk I Kidang suba masusupan ka alase. Lantas paderepe ngalanturang nganyi padine Nanang Brangkuse sambilang makekedekan nyatuayang unduk I Kidang nomplok Men Brangkus kanti ulung maleging.

I Ketut Kaler maorahan teken Nanang Brangkus, ia busan suba masang jaet, sambilanga matutuhang jaetne. I Ketut Kaler nunden Nanang Brangkus ningal-ningalin mani. Nang Brangkus ngencolang masaut demen, kone apang taen naar semalin kidang. Sawetara buin telune, pasemengan pesan I Cetrung madingehang ada nak ngeling di abian Nanang Brangkuse. Lantas makeber I Cetrung luh ka abian Nanang Brangkuse. Tengkejut pesan I Cetrung nepukin I Kidang slegak-slegak das- dasan mati, sawireh baongne kena jaet.

Cetrung masemaya lakar ngwales pitresnane I Kidang, lantas I Cetrung makeber ngalih somah teken panakne. Ajahan pesan ia teka pakeber-ber lantes matinggah di pagehan abian Nang Brangkuse. Saget teka Nanang Brangkus negen kranjang lakar ngalap kacangne. Cetrung muani ngeka daya, ia ajak panakne lakar mejunin matan Kidange, Cetrung luh ngalihang uled, apange bek paklenyuk matan Kidange misi uled. Di subane Nang Brangkus teked dini I Kidang apang tusing pesan mangkihan, apanga kadena I Kidang mati. Kabenengan di sampingne ada bangken bikul ane mabo pengit, sinah suba kadene bon bangken Kidange. Lantas I Cetrung ajake panakne mencegan di kuping I Kidang sambilange mejunin matane.

Kacerita jani Nang Brangkus suba teked di abiane. Gageson ía nelokin jaet pisagane. Nang Brangkus masuryak padidiane ulian demen lakar maan be Kidang. Sakewala mara tatasanga, dadi mabo pengit, matane suba uledan, berek, bengkang basangne. Lantas Nang Brangkus nyemak aritne, jaete anggeta kanti pegat. Nang Brangkus nyeruyung sawireh tengkejut tomploka ban I Kidang ane tan pasangkan makecos laut malaib nongklang masusupan ka alas cabole ane ada di teben carik Nang Brangkuse. I Cetrung magending nguci duur tungguhan kacange, atine liang pesan nepukin sawitrane, I Kidang prasida rahayu. 


\section{Nilai-Nilai yang Terkandung dalam Satua Cetrung}

Satua Cetrung merupakan karya sastra yang mengandung nilai-nilai adiluhung serta dapat dijadikan pedoman dalam kehidupan. Wellek dan Warren (1990:317) mengatakan bahwa nilai suatu karya sastra tersebut hendaknya dipandang sebagai suatu yang sudah melekat pada hakekat dan fungsi karya sastra itu sendiri, sehingga penilaiannya tidak berdasarkan pada cerita diluar sastra.

Mengkaji sebuah satua sebagai produk kebudayaan Bali, membutuhkan konsepkonsep nilai yang relevan sehingga nantinya dapat dipergunakan untuk mengetahui nilai-nilai yang terkandung di dalamnya. Karya-karya sastra Bali mengandung dua hal pokok yaitu: (1) mempunyai nilai-nilai artistik tersendiri (2) mempunyai nilai-nilai spiritual kemanusiaan atau kebenaran yang universal yang hakiki (Agastia, 1980:2).

Yudibrata (dalam Atmaja, 1988:18-20) mengatakan nilai adalah aspek tingkat kebijakan dan kegunaan yang dimiliki sesuatu, yang dalam hal karya sastra nilai-nilai itu dianggap saling berhubungan secara harmonis. Adapun nilai-nilai yang dirumuskan oleh Yudibrata antara lain: 1) nilai agama meliputi nilai religious, magis, kepercayaan, dan nilai spiritual, 2) nilai logika meliputi nilai intelektual, ilmiah (pengetahuan), dan nilai empiris, 3) nilai etika meliputi nilai moral, sopan santun, manusiawi, etika, dan lain-lain. dan 4) nilai estetika meliputi nilai keindahan, nilai keseimbangan, keagungan, keasrian, dan lain sebagainya.

\section{a. Nilai Agama}

Menurut Yudibrata (dalam Atmaja, 1988: 21), menyatakan bahwa nilai agama meliputi: nilai religius/nilai ketuhanan, nilai magis, nilai kepercayaan, dan nilai spiritual. Nilai ketuhanan pada umumnya selalu ada dalam karya sastra. Pengarang sering menyebutkan nama-nama dewa yang dipuja. Pada awalnya sastra adalah religius. Kalau agama lebih menunjukkan pada kelembagaan kebatinan terhadap Tuhan, atau kepada dunia atas aspek yang resmi, maka religiusitas lebih melihat aspek di dalam lubuk hati, riak getaran hati nurani pribadi, sikap personal yang sedikit banyak misteri bagi orang lain (Sentana, 2016). Dalam Satua Cetrung, nilai religius tercermin dari dari peristiwa-peristiwa yang dialami tokoh Cetrung dan Kidang yang mana di dalam peristiwa-peristiwa tersebut pada dasarnya mempersoalkan hal-hal yang berhubungan dengan keagamaan. Hal tersebut dapat dilihat dalam kutipan berikut:

"Aahh... Cetrung.. ne mara pangrencana, dumadak mapikolih. Yan suba pada rahayu nah ditu jalan raosang buin, jani alihang panake uled malu pang ia seger, mani pang nyidaang kecag-kecog di padine!"

Terjemahan:

“Aahh...Cetrung.. ini baru rencana, semoga berhasil. Kalau sudah semua selamat, ya nanti dibicarakan lagi, sekarang carikan dulu anakmu ulat agar dia sehat, besok supaya bisa melompat-lompat di padi!"

Kutipan di atas dapat dijelaskan bahwa tokoh Kidang mengucapkan "dumadak mapikolih" yang artinya "semoga berhasil", di mana Kidang mengharapkan Ida Sang 
Hyang Widhi memberikan restu agar ia berhasil menjalankan rencana yang ia buat dengan Cetrung untuk menyelamatkan nyawa anak Cetrung.

\section{b. Nilai Logika}

Menurut Yudibrata (dalam Atmaja, 1988:18-20) nilai logika meliputi nilai intelektual, nilai ilmiah (pengetahuan), dan nilai empiris. Namun dalam Satua Cetrung ini sangat jelas mengandung nilai intelektual. Intelektual sebagai kumpulan atau totalitas kemampuan seseorang untuk bertindak dengan tujuan tertentu, berpikir secara rasional, serta menghadapi lingkungan secara efektif.

Nilai-nilai intelektual dalam Satua Cetrung, dapat diketahui dari ucapan-ucapan seperti yang tampak dalam kutipan berikut:

"Adeng-adeng malu memene. Kenken panake? Lacur kenapa ia? Orahin icang!", I Cetrung muani netesang nakonin somahne. "Aruuh bli, padine ene, tongos iraga masebun suba pada kuning. Icang busan madingehang Nanang Brangkus nyatua ajak memene, mani padine ene lakar panyine. Sinah suba panake lakar ejuka, sawireh ia tonden kerep bulunne, tusing nyidang makeber joh."

Terjemahan:

"Pelan-pelan dulu bu. Kenapa anak kita? Malang kenapa dia? Beri tahu saya!", I Cetrung jantan bertanya kepada istrinya. "Aduuh bli, padi ini, tempat kita bersarang sudah kuning semua. Tadi saya mendengar Nanang Brangkus bicara dengan istrinya, besok padi-padi ini akan dipanen. Pasti anak kita akan diambil, karena bulunya belum tumbuh bagus, tidak bisa ia terbang jauh."

Kutipan di atas menjelaskan bahwa Cetrung betina sangat menghawatirkan anaknya akan diambil oleh para petani yang akan memanen padi tempat mereka bersarang, ia menyadari bahwa anaknya baru lahir dan bulunya belum tumbuh semua sehingga belum bisa terbang, dan ia pun tak berdaya tak bisa menerbangkan anak nya dari sarang itu. Nilai logikanya adalah saat mendengar padi tempat Cetrung bersarang akan dipanen, Cetrung langsung merasakan kekhawatiran dan kesedihan yang mendalam terhadap keselamatan anaknya. Ucapan-ucapan lain yang mencerminkan nilai logika dapat dilihat pada kutipan berikut.

"Trung... icang bareng sebet ngenehang unduk caine, icang uli lawas suba masewitra ajak cai, jele melah icang misadia ajak cai. Angkihan anggo icang toh melanin cai...nah kene.. Trung.. mani disubane teka paderepe makire nganyi padin Nang Brangkuse... nah kene ban madaya..." Lantas I kidang mamunyi kisi-kisi di kuping il Cetrunge, sambilanga makenyem. 
Terjemahan:

"Trung... saya ikut sedih memikirkan masalahmu, saya dari dulu sudah berkawan denganmu, sedih senang saya bersedia denganmu. Nyawa saya pertaruhkan untuk membelamu...nah begini.. Trung.. besok sesudah para pemanen akan mulai memanen padinya Nanang Brangkus...nah begini akal kita..." Lalu I Kidang berbisikbisik di kuping Cetrung, sambil tersenyum.

Kutipan di atas menjelaskan bahwa setelah I Kidang mengetahui permasalahan yang dihadapi oleh sahabatnya I Cetrung, ia tidak tinggal diam, namun ia mencari akal dan solusi, membuat rencana untuk menyelamatkan nyawa anak Cetrung. Dari kutipan itu kita dapat melihat bahwa apabila kita menemui masalah hendaknya kita tidak boleh berputus asa, namun harus mencoba menghadapi masalah dengan cara berusaha mencari solusi atau pun jalan keluar dari masalah tersebut.

\section{c. Nilai Etika}

Yudibrata (dalam Atmaja 1988:18-20) menyatakan nilai etika dapat meliputi nilai moral, sopan santun, manusiawi dan etika Etika adalah bentuk pengendalian diri. Pengendalian diri dalam pergaulan mengenal tingkah laku yang baik disebut dengan tata susila. Nama lainnya adalah etika. Nilai etika yang terkandung dalam Satua Cetrung dapat dilihat dalam kutipan berikut:

"Aduuh bli Kidang, suksma pesan, sakewala apa anggo icang ngawales pitulung beline, icang lakar setata inget ngelah sawitra ane melah sekadi bli."

Terjemahan:

"Aduuh bli Kidang, terimakasih banyak, tetapi apa yang bisa saya lakukan untuk membalas pertolongan bli ini, saya akan selalu ingat punya sahabat yang baik seperti bli."

Kutipan di atas menjelaskan bahwa Cetrung tidak lupa mengucapkan rasa terima kasih atas pertolongan yang diberikan oleh I Kidang. Nilai etika yang dapat kita lihat yaitu apabila ada orang lain memberikan bantuan kepada kita hendaknya kita mengucapkan rasa terima kasih. Terima kasih adalah bahasa paling sederhana untuk mengungkapkan apresiasi terhadap suatu hal. Dengan mengucapkan terima kasih terdapat energi positif yang dirasakan baik oleh si pemberi maupun si penerima. Energi positif inilah yang diperlukan untuk menciptakan komunikasi yang baik dalam masyarakat (Sugoto, Dektisa, and Cahyadi ,2011).

Kutipan lain yang menggambarkan nilai etika dan kesetiaan adalah sebagai berikut.

"Bli Kidang... icang lakar mautsaha nulungin Bli... sasidan-sidan icang ngawales tresnan Bline teken pianak icange. Nengil Bli malu dini!", lantas I Cetrung makeber ngalih somah teken panakne. Ajahan pesan ia teka pakeber-ber lantes matinggah 
di pagehan abian Nang Brangkuse. "Bli Kidang... jani suba sapatutne panumayan icange nulungin Bli.", keto I Cetrung muani negesang unduk kasujatian pasawitrane. "Sakewala ampura yen saget icang tusing prasida nulungin Bli."

Terjemahan:

"Bli Kidang... saya akan berusaha menolong bli... semampunya saya akan membalas kasih sayang bli terhadap anak saya. Diamlah bli dulu di sini!", lalu I Cetrung terbang mencari istri dan anaknya. Hanya sebentar mereka dating beterbangan lalu hinggap dip agar kebun kacangnya Nang Brangkus. "Bli Kidang... sekarang sudah waktunya saya menolong bli.", begitu I Cetrung jantan meyakinkan tentang pertemanan mereka yang sejati. "Namun, maafkan saya jikalau tidak mampu menolong bli."

Kutipan di atas tampak jelas menunjukkan kata-kata yang diucapkan sopan dan beretika. Cetrung dengan sepenuh hati akan berusaha membalas budi kepada I Kidang, ia meyakinkan akan berusaha menolong dengan segenap kemampuannya. I Cetrung juga memohon maaf apabila nantinya tidak berhasil menolong Kidang. Nilai etika yang dapat kita lihat pada kutipan tersebut adalah apabila kita memberikan pertolongan atau bantuan kepada orang lain, hendaklah menolong dengan penuh keikhlasan.

\section{Kesimpulan}

Masatua mempunyai fungsi sebagai penyampaian pesan dan amanat yang mengandung unsur pendidikan, khususnya dalam etika dan moral. Agar pesan dan amanat tersebut sampai, penutur harus bisa menuturkan dengan cara yang menarik. Fungsi utamanya adalah pengukuhan norma-norma sosial dan nilai-nilai yang menjadi pegangan tingkah laku masyarakatnya. Norma dan nilai tersebut antara lain tanggung jawab, kreatif, ketaatan pada orangtua, kewaspadaan, keikhlasan, persahabatan, kesederhanaan, kesetiaan, etika, kepercayaan dan lain-lain. Satua Cetrung merupakan karya sastra yang mengandung nilai-nilai adiluhung serta dapat dijadikan pedoman dalam kehidupan. Dalam Satua Cetrung dapat dilihat adanya nilai-nilai agama, nilai logika, dan nilai etika.

\section{Daftar Pustaka}

Arissandi, Devi, christina T Setiawan, and Rahayu Wiludjeng. 2019. "2 3 123." Jurnal Borneo Cendekia 3(2): 40-46.

Atmaja, Jiwa. 1988. Masyarakat Sastra Indonesia. Denpasar: Himsa.

Chaer, Abdul. 2007. Linguistik Umum. Jakarta: Rineka Cipta.

Dewi, K R. 2019. "Tradisi Masatua Pada Keluarga Hindu." ... : Jurnal Ilmu Sosial Dan Humaniora: 234-49.

http://jayapanguspress.penerbit.org/index.php/ganaya/article/view/364.

Dinas Pendidikan Pemuda dan Olah Raga Provinsi Bali. 2008. Kurikulum Mata Pelajaran Bahasa Bali SMA. Denpasar.

Klinik Pendidikan dan Dewan Pendidikan Kabupaten Tabanan. 2017. Pupulan Satua Bali II. Tabanan: Swadaya. 
Melestarikan, Untuk, and Bahasa Bali. 2021. "Masatua Sebagai Salah Satu Kearifan Lokal Bali Untuk Melestarikan Bahasa Bali." 1(1): 74-82.

Pradnya Paramitha, Ni Made Ayu Susanthi. 2020. "Meningkatkan Mutu Nilai Kemanusiaan Pada Anak-Anak Melalui Satua Men Tiwas Teken Men Sugih (Sebuah Kajian Semiotika)." Jurnal Penjaminan Mutu 6(1): 108.

Sentana, Gek Diah Desi. 2016. "Representasi Konflik Dan Nilai Kehidupan Dalam Satua I Rare Angon." (2): 18-30.

Sugiyono, 2012. Metode Penelitian Kuantitatif Kualitatif dan R\&D. Bandung: Alfabeta.

Sugoto, MC, A Dektisa, and J Cahyadi. 2011. "Kajian Iklan Layanan Masyarakat Tentang Pentingnya Mengucapkan Terima Kasih Bagi Para Remaja Di Surabaya." Nirmana. http://ced.petra.ac.id/index.php/dkv/article/view/18133.

Suwija, I Nyoman. 2011. Widia Sari 1. Denpasar: Sri Rama.

Tinggi, Sekolah, Agama Hindu, Negeri Mpu, and Kuturan Singaraja. 2021. "Internalisasi Nilai Pendidikan Karakter Melaui Satua i Karuna." 2(1).

Wellek dan Weren. 1990. Theory of Literatur (Diterjemahkan oleh keluarga Mahasiswa Sastra Indonesia Fakultas Sastra dan Kebudayaan). Yogyakarta: Universitas Gajah Mada. 